SOCIAL EXCLUSION AND DECISION MAKING

RUNNING HEAD: SOCIAL EXCLUSION AND DECISION-MAKING

\title{
Decision-makers are resilient in the face of social exclusion
}

Marie Juanchich ${ }^{\mathrm{a}}$, Lukasz Walasek ${ }^{\mathrm{b}}$ and Miroslav Sirota ${ }^{\mathrm{a}}$

Authors' affiliations:

${ }^{a}$ University of Essex, Department of Psychology

${ }^{\mathrm{b}}$ University of Warwick, Department of Psychology

\section{Corresponding author:}

Marie Juanchich

Address: Department of Psychology, University of Essex, Wivenhoe Park, CO4 3SQ,

Colchester, UK.

Email: m.juanchich@essex.ac.uk

Tel: (+44) 1206873812

Lukasz Walasek

Address: University of Warwick, Department of Psychology, Coventry CV4 7AL, UK.

Email: L.Walasek@warwick.ac.uk

Tel: (+44) 2476523523

Miroslav Sirota

Address: Department of Psychology, University of Essex, Wivenhoe Park, CO4 3SQ,

Colchester, UK.

Email: msirota@essex.ac.uk

Tel: (+44) 1206874229

This research was supported by the Leverhulme Trust grant RP2012-V-022. Raw data and source code for the analysis will be posted online on publication and are available now from the authors. 
Pre-publication version

SOCIAL EXCLUSION AND DECISION MAKING 
Pre-publication version

SOCIAL EXCLUSION AND DECISION MAKING

\begin{abstract}
A growing body of evidence suggests that social exclusion impairs people's capacity for active deliberation and logical reasoning. Building on this finding and on the postulate from the dual-process theory that analytical thinking is essential in order to make good judgments and decisions, we hypothesised that social exclusion will alter judgment and choice behaviour. We tested this hypothesis in three experiments in which social exclusion was manipulated using the Cyberball paradigm, an online ball-tossing game in which participants either received the ball a fair number of times or were excluded by the other two players. We focused on a range of tasks designed to be sensitive to participants' ability to engage in analytical thinking and careful deliberation, including the Cognitive Reflection Test (Experiment 1) and a set of anchoring, intertemporal preference, disjunction and confidence tasks (Experiments 2 and 3). Our results unanimously failed to support the hypothesis that social exclusion influences people's judgments and decision-making. We discuss the implications of our findings for social exclusion theory.
\end{abstract}

Key words: social exclusion; decision-making performance; deliberation; cognitive impairment 
Pre-publication version

\section{SOCIAL EXCLUSION AND DECISION MAKING}

\section{Decision-makers are resilient and adaptive in the face of social exclusion}

One of the fundamental aspects of human social interaction is the omnipresent risk of social rejection. Existing empirical work consistently shows that social exclusion produces a wide range of negative behavioural, cognitive, emotional and physiological consequences (DeWall \& Bushman, 2011). A growing body of evidence indicates that excluded individuals perform worse in cognitively demanding tasks (e.g., Baumeister, DeWall, Ciarocco, \& Twenge, 2005; Baumeister, Twenge, $\&$ Nuss, 2002). We posit that the decrement in cognitive functions disrupts individuals' capacity to engage in deliberative reasoning. Building on the dual-process theories of human reasoning, we propose that social exclusion affects judgments and decisions.

\section{Social exclusion impairs executive functions.}

Individuals who anticipate, experience or describe past instances of social exclusion perform worse in tasks that measure executive cognitive function, such as intelligence, working memory, information encoding, or information search (Baumeister et al., 2002; Hawes et al., 2012; Lustenberger \& Jagacinski, 2010; see Williams, 2007 for an overview; Xu et al., 2017). For example, Baumeister and colleagues (2002) compared the scores of 40 undergraduate students in a General Mental Abilities Test ${ }^{1}$ (Janda, 1996). Beforehand, participants completed a personality test, which was followed by false feedback. One third of the sample were told that their personality scores indicated that they were more likely to end up being alone in the future (exclusion group). The remaining participants were split into two control conditions where they were either told that they will spend the rest of their life surrounded by people close to them (inclusion group), or that they were likely to experience

\footnotetext{
${ }^{1}$ Participants did not complete the whole test but were asked to provide a maximum number of correct answers in six minutes.
} 
Pre-publication version

\section{SOCIAL EXCLUSION AND DECISION MAKING}

misfortune in later life due to poor health (misfortune group). The results showed a considerable difference in mental ability scores - participants who anticipated future exclusion performed considerably worse $(d=.98$ for the pairwise comparison of exclusion and misfortune groups). Consistent effects have been found in studies where feelings of exclusion were elicited by reminiscing about past exclusion (Chen, Williams, Fitness, \& Newton, 2008) or by experiencing exclusion in an online ball-tossing game (Lustenberger \& Jagacinski, 2010; Xu et al., 2017). For example, Xu et al. (2017) showed that participants ( $N$ =34) exhibited a significantly smaller memory capacity after being excluded in the Cyberball game than after being included in the game.

Three main accounts explain why social exclusion may negatively impact basic cognitive executive functions: (1) because of an increased negative mood and anxiety and reallocation of cognitive resources to their management (Tice \& Baumeister, 1990); (2) because of a decrement in motivation for cognitively demanding tasks (Baumeister et al., 2002; Buhs, Ladd, \& Herald, 2006; Lustenberger \& Jagacinski, 2010; Twenge, Catanese, \& Baumeister, 2003) - note however, that social exclusion is expected to have the opposite effect (boosting motivation) for tasks that have a social component (Maner, Schaller, DeWall \& Baumeister, 2007; Williams \& Sommer, 1997); (3) because of a change in self-regulation (Baumeister et al., 2005; Twenge, Catanese, \& Baumeister, 2002a; Twenge et al., 2003). Shilling and Brown (2016) further argued that the decrement in cognitive resources is strategic and evolutionary adaptive. Following social exclusion people would allocate more resources to tasks that are socially relevant, whereas people would allocated less resources to tasks that are not socially relevant.

The common theme underlying all of the accounts of the effect of social exclusion on executive functions is that excluded individuals show a reduction in their ability to engage 
Pre-publication version

\section{SOCIAL EXCLUSION AND DECISION MAKING}

in deliberative thinking: because of lower cognitive resources, lack of motivation or because of a weakened ability to self-regulate.

\section{Social exclusion, judgment and decision-making}

The dual-process theories of human cognition are a useful framework with which to map the possible effects of social exclusion. These theories posit that people's thinking can rely on two distinct processes (Bargh, 1994; Epstein, Pacini, Denes-Raj, \& Heier, 1996; Evans, 2008; Kahneman \& Frederick, 2005; Kahneman, Knetsch, \& Thaler, 1991; Lichtenstein \& Slovic, 2006; Sanfey \& Chang, 2008; Sloman, 1996; Sloman, 2002; Stanovich \& West, 2000; Stanovich, 1999; Tversky \& Kahneman, 1974). On one hand, people can process information intuitively and quickly (often called system 1), with relatively little cost in terms of cognitive resources. Those intuitive processes are often associated with biases and errors in judgment and choice. On the other hand, people can be more deliberate, in which case information processing is more systematic, slower and more cognitively costly. Deliberation (also called analytical thinking or system 2) is generally associated with better performance in cognitive tasks that require more cognitive effort. The argument that intuitive thinking always results in normatively suboptimal decision quality continues to be challenged (Arkes, Gigerenzer, \& Hertwig, 2016), but it is widely accepted that deliberation does shape judgments and decision-making (Cacioppo \& Petty, 1982; Gilovich, Griffin, \& Kahneman, 2002; Juanchich, Dewberry, Sirota, \& Narendran, 2016; Kahneman \& Frederick, 2005; Toplak, West, \& Stanovich, 2014).

From the perspective of the dual-process theory, if the effect of social exclusion should lead to a lower reliance on deliberation, then, it should predict the judgments and choices that people make. 
Pre-publication version

\section{SOCIAL EXCLUSION AND DECISION MAKING}

Previous studies on the role of social exclusion in decision-making focused on risky choices. This line of research showed that participants who were excluded in a Cyberball game were more likely to take risks and that this effect was fairly long lasting (e.g., affecting the trials 41 to 80 in an Iowa Gambling Task; Buelow, Okdie, Brunell, \& Trost, 2015; in the 6th to 10th decision in an investment game; Walasek, Juanchich, \& Sirota, 2018). The effect of social exclusion on risky decision-making was further examined in tasks requiring more or less analytical thinking, with the expectation that social exclusion would only affect performance in tasks that required analytical thinking (Buelow \& Wirth, 2017). For example, social exclusion was not expected to predict decision-making in the Balloon Analogue Risk Task (Lejuez et al., 2002) because it does not require deliberation due to the randomness of balloons popping. However, social exclusion was posited to predict the decisions made in the Game of Dice Task because it requires some deliberation, especially in the later stage of the game (Brand et al., 2005). Indeed, social exclusion did not affect risky decision-making in the Balloon Analogue Risk Task, but did so in the Game of Dice Task (Buelow \& Wirth, 2017).

There are two main limitations to the conclusions that we can draw from the relationship between social exclusion and risky decision-making. First, it is often unclear what the optimal level of risk aversion is and what a "good performance" is in a risky game. As such, although exclusion appears to lead to more risk-seeking behaviour, we cannot state whether this corresponds to an adaptive or maladaptive response. Secondly, and similarly, the relationship between risky decision-making and deliberation is not straightforward. It seems, for example, to vary according to the measure of risky decision-making used (Buelow \& Wirth, 2017) and tends to change over time - with later decisions made in the later trials depending more on deliberation than the earlier ones (Brand, Recknor, Grabenhorst, \& Bechara, 2007). In order to explore whether social exclusion leads to a decrement in 
Pre-publication version

\section{SOCIAL EXCLUSION AND DECISION MAKING}

analytical thinking and deliberation, we now turn to higher-order cognitive tasks of judgment and decision-making.

According to a normative theory of decisions, the optimality of decisions is based on people's ability to follow basic rules of logic and mathematics which require some analytical thinking (Toplak, West, \& Stanovich, 2011). The failure to follow these rules can result in judgments or decisions that are suboptimal and can therefore often be qualified as biases (Keren \& Teigen, 2004). The decrement to people's capacity to engage in analytical thinking can also lead to shifts in preferences, even when the optimality is not strictly defined (e.g., the risky choice paradigms discussed earlier) ${ }^{2}$. There is a range of tasks which were developed to assess various biases in which the absence and presence of these biases can be used as an indicator of people's ability to engage in deliberate reasoning and analytical thinking (Toplak et al., 2011; Tversky \& Kahneman, 1974). Interestingly, performance in normative decisionmaking tasks is also related to decision-making performance in real life (Juanchich et al., 2016; Pennycook, Fugelsang, \& Koehler, 2015) and is sometimes used as a generic index of decision-making competence (Bruine de Bruin, Parker, \& Fischhoff, 2007). In the present paper, we have used a library of judgment and decision-making tasks to establish whether the experience of being socially excluded diminishes people's ability to engage in analytical thinking and hence leads to either a decrement in decision-making performance or a shift in their preferences.

\section{Present research}

\footnotetext{
${ }^{2}$ Often, models of choice are also models of judgment, in which case biases of judgments are biases of preference. In the present paper, we have considered both judgments that can underpin complex choice behaviour (e.g. probabilistic reasoning) and preferences themselves (e.g. intertemporal choice). The shift in preference can be treated as a bias with respect to the assumptions of the rational economic theory, as the model assumes stable and consistent preferences. However, we have abstained from arguing that a shift in a particular direction (e.g. more patience) is equivalent to biased preference, and instead have focused on the effect that would be caused by a decrease in one's ability to deliberate and engage in analytical thinking.
} 


\section{SOCIAL EXCLUSION AND DECISION MAKING}

In three experiments, we induced feelings of social rejection using a virtual balltossing game paradigm (Zadro, Williams, \& Richardson, 2004). In these experiments we examined whether social exclusion impairs decision-making performance in a range of tasks. Our experiments complement existing work by testing the corollary consequence of the effect of social exclusion on cognitive capacity by assessing the effect of social exclusion on the judgments and choices that require deliberation. Further, our objective is to provide insights into possible pathways through which social exclusion could impact decision-making by assessing the role of feelings of exclusion and emotion in decision-making.

In Experiment 1, we compared the performance of excluded and included individuals in the Cognitive Reflection Test, which measures people's tendency to inhibit their intuition and rely on a more deliberative form of reasoning to solve three mathematical problems. By its very definition, the concept of cognitive reflection is linked to the notion of deliberation. Indeed, if people are able to inhibit their intuition they are more likely to deliberate (Frederick, 2005). Cognitive reflection performance is positively associated with the individual differences in deliberative reasoning (e.g., rational decision-making style) (Dewberry, Juanchich, \& Narendran, 2013).

In Experiments 2 and 3, we used four different and well-established judgment and decision-making tasks: anchoring, temporal discounting, conjunction fallacy and confidence. Participants' judgments and decisions in these tasks are influenced by the mode of processing as summarised in Table $1^{3}$. Consistent with the previous literature on the role of deliberation in judgment and choice, we expected that social exclusion would lead to a stronger anchoring effect, a preference for the lower immediate reward, higher rates of failures in probabilistic

\footnotetext{
${ }^{3}$ We have drawn evidence from a broad research area incorporating various designs and measures. These include, for example, correlational designs showing a relationship between deliberation tendencies and decisionmaking performance or experimental designs demonstrating that a reduced working memory capacity led to a decrement in decision-making performance.
} 
Pre-publication version

SOCIAL EXCLUSION AND DECISION MAKING

reasoning, and a stronger tendency to show higher levels of confidence in the accuracy of their decisions. 
Pre-publication version

SOCIAL EXCLUSION AND DECISION MAKING

Table 1

Relationship between deliberation and judgment and decision-making in the five tasks examined in Experiments 1-3.

\begin{tabular}{|c|c|c|}
\hline Tasks & Definition & Deliberation and judgment and decision outcome \\
\hline $\begin{array}{l}\text { Cognitive } \\
\text { reflection test }\end{array}$ & $\begin{array}{l}\text { Measures a person's ability to suppress an } \\
\text { intuitive response in three mathematical } \\
\text { puzzles. High scores correspond to a higher } \\
\text { ability to engage in deliberate reasoning. }\end{array}$ & $\begin{array}{l}\text { Lower deliberation is associated with lower scores } \\
\text { (Frederick, 2005; Juanchich et al., 2016) }\end{array}$ \\
\hline Anchoring & $\begin{array}{l}\text { Numerical judgments tend to be influenced by } \\
\text { (i.e. closer to) another anchor value, which } \\
\text { can be provided or self-generated by the } \\
\text { participant. }\end{array}$ & $\begin{array}{l}\text { Lower deliberation is associated with stronger anchoring } \\
\text { (Gal, Mrva, \& Gajdosova, 2014; Teovanović, Knežević, } \\
\text { \& Stankov, 2015) } \\
\text { See also the following for null effects: (Oechssler, } \\
\text { Roider, \& Schmitz, 2009; Plessner \& Czenna, 2008; } \\
\text { Welsh, Burns, \& Delfabbro) }\end{array}$ \\
\hline $\begin{array}{l}\text { Intertemporal } \\
\text { choice }\end{array}$ & $\begin{array}{l}\text { Measures people's tendency to discount } \\
\text { future rewards. Impatient individuals choose } \\
\text { smaller rewards that can be obtained sooner } \\
\text { instead of larger rewards obtained later in } \\
\text { time. }\end{array}$ & $\begin{array}{l}\text { Lower deliberation is associated with a preference for } \\
\text { immediate and lower rewards (Campitelli \& Labollita, } \\
\text { 2010; Ghazal, Cokely, \& Garcia-Retamero, 2014; } \\
\text { Oechssler et al., 2009; Welsh et al.) }\end{array}$ \\
\hline Conjunction & $\begin{array}{l}\text { The erroneous belief that the probability of } \\
\text { two events occurring is more likely than the } \\
\text { probability of one of these two events } \\
\text { occurring. }\end{array}$ & $\begin{array}{l}\text { Lower deliberation is associated with more conjunction } \\
\text { fallacy (Alos-Ferrer \& Hugelschafer, 2012; Hoppe \& } \\
\text { Kusterer, 2011; Liberali, Reyna, Furlan, Stein, \& Pardo, } \\
\text { 2012; Noori, 2016; Oechssler et al., 2009; Toplak et al., } \\
\text { 2011). } \\
\text { See also the following for null effects: (Albaity, } \\
\text { Rahman, \& Shahidul, 2014; Welsh et al.; Zhou, He, } \\
\text { Yang, Lao, \& Baumeister, 2012) }\end{array}$ \\
\hline Confidence & $\begin{array}{l}\text { Tendency to overestimate one's ability to } \\
\text { provide a correct answer or perform better } \\
\text { than others in general. }\end{array}$ & $\begin{array}{l}\text { Lower deliberation is associated with higher levels of } \\
\text { confidence (Hoppe \& Kusterer, 2011; Noori, 2016; } \\
\text { Sinayev \& Peters, 2015; Teovanović et al., 2015) }\end{array}$ \\
\hline
\end{tabular}


Pre-publication version

\section{SOCIAL EXCLUSION AND DECISION MAKING}

Methodological statement. We have reported all of the experiments we conducted on individual decision-making and all of the variables measured. For all the experiments, we have reported statistical inferences using both frequentist and Bayesian results of null hypothesis testing to quantify support for our hypotheses and for the null hypothesis. A data screening procedure has been followed consistently and is detailed in the Participants section of each experiment. The experimental materials and data are available on the Open Science Framework: http://j.tinyurl.com/kov7qy2.

\section{Experiment 1}

In Experiment 1, we directly tested whether social exclusion influenced people's ability to inhibit automatic responses to employ an analytical thinking mode. We used the Cognitive Reflection Test (Frederick, 2005) as our dependent variable, where higher scores demonstrate a greater ability to inhibit intuitive and incorrect answers.

\section{Method}

Participants. The experiment was powered to detect a small to medium effect size (d $=.40$, power $=.80)$ based on the past work that reported medium to large effect sizes for the effect of social exclusion on cognitive processes (Baumeister et al., 2002). We initially aimed to gather a sample size of 172 participants. We planned our data collection via Amazon Mechanical Turk (AMT), and we adjusted our sample size upward because of the usual attrition rate $(+25 \%)$ and because a large proportion of AMT workers know the Cognitive Reflection Test (+50\%; Toplak et al., 2014). This computation led us to select a sample of 330 participants.

Data screening. A total of 328 participants completed the online experiment. We followed a general four-stage data screening procedure in all reported experiments that were 
Pre-publication version

\section{SOCIAL EXCLUSION AND DECISION MAKING}

conducted via AMT. First, we reviewed the time that participants took to complete the survey $(M=605$ seconds, $S D=210)$. Participants whose completion time was either two standard deviations below or above the sample mean (185 and 1,025 seconds, respectively) were excluded $(n=12)$. This step was necessary to ensure that the participants took the requisite time to complete the Cyberball game and avoided a long delay between the game and the rest of the survey. Second, we screened out participants who reported having problems accessing the Cyberball game $(n=20)$. Third, we screened our data for duplicate responses (based on the unique AMT ID) and retained only the earlier responses $(n=1)$. Fourth, we excluded participants who had taken part in a similar experiment we ran: none in this case.

Since the CRT has been widely used in psychological research, we assessed whether our participants had previously completed this particular task (Toplak et al., 2014). Half of the participants reported knowing at least one of the items of the CRT $(n=174)$ and scored better in the CRT than participants who were unfamiliar with the task. However, knowledge of the CRT did not interact with the social exclusion manipulation, $F(1,293)<1$ and we therefore chose to retain responses from participants who knew the CRT. Our final sample size $(N=294,46 \%$ male $)$ was sufficient to detect small effect sizes $(d=0.33)$. Participants' ages ranged from 18 to $71(M=33.46, S D=11.45)$.

Design. The experiment featured two between-subjects conditions: social inclusion and social exclusion. Our key dependent variable was the number (out of 3) of correct answers on the CRT task.

Materials and procedure. After giving informed consent, participants were introduced to the Cyberball game. Cyberball is an online ball-tossing game created to manipulate social exclusion (Williams \& Jarvis, 2006). The game was introduced to participants with the aim of practising mental visualisation skills. Participants read that the game involved "playing a 
Pre-publication version

\section{SOCIAL EXCLUSION AND DECISION MAKING}

ball-tossing game with the computer" instead of the classic "with other participants who are logged on at the same time". Although our wording was ambiguous regarding exactly who was controlling the players, we chose to avoid simply saying that participants would play with other people. Previous work has shown that even when people are explicitly told that they will play with two computer-operated players, this does not hinder the impact of social exclusion (Zadro et al., 2004).

The social manipulation was implemented according to the number of ball tosses that the participants received. In the social inclusion condition, participants received the ball approximately 10 times out of 30 ball tosses throughout the game. In the social exclusion condition, participants received two tosses at the beginning of the game and none of the remaining 28 ball tosses. In both conditions, participants played for an average of two minutes (the duration varied slightly according to how quickly participants sent the ball back). Based on how well established the Cyberball paradigm is in the literature, and its effectiveness in eliciting feelings of exclusion, we chose it as our main method for inducing feelings of being socially excluded.

After completing the Cyberball game, participants read and answered the three items of the CRT (Frederick, 2005) presented on the same page and in a different order for each participant. The items were the bat and ball, the lily pad and the widget problems (see Appendix A). Each item had an intuitive and incorrect answer that sprung to mind and which needed to be inhibited in order to find the correct answer. Participants' responses were coded as correct (1) or incorrect (0). The scale had a good level of reliability (Cronbach's alpha = .71). We measured the time participants spent answering the CRT.

Next, participants completed four measures designed to assess their experience during the ball-tossing game (Zadro et al., 2004). The questionnaire (see Appendix B) included 
Pre-publication version

\section{SOCIAL EXCLUSION AND DECISION MAKING}

perception of exclusion, four fundamental psychological needs and mood. Perception of exclusion covered two aspects: feeling of exclusion, measured via two items, and the perceived number of ball tosses received during the game. The four fundamental needs were belongingness, self-esteem, feeling of control and feeling of meaningful existence, each measured with three items. Participants responded on a five-point Likert scale ranging from 1: Not at all to 5: Very much. The participants' moods were measured with the short Positive and Negative Affect Schedule (PANAS, 10 items, Watson, Clark, \& Tellegen, 1988) which was also used in Baumeister et al. (2002, Experiment 3). Responses were given on a 5-point Likert scale ranging from 1: Not at all to 5: Completely. All the scales reached a satisfactory internal reliability (Cronbach's alpha between .79 and .92) and were averaged to create index variables for respective constructs. Mood was computed by subtracting the average score for the five negative mood items from the average score for the five positive mood items. Therefore, higher scores represented a more positive mood.

The experimenter did not interact in any way with the participants during the experiment. Participants were then debriefed and informed that their co-players were computer-based. We also emphasised that participants were randomly allocated to two game conditions: inclusion or exclusion (Baumeister et al., 2005). Then, participants completed a self-esteem boosting exercise where they listed their best qualities (Walasek, Matthews, \& Rakow, 2015) followed by an assessment of their current mood and self-esteem level.

Finally, all participants reported whether they experienced any issues with the Cyberball game, if they had played Cyberball before and if they had encountered any of the three CRT problems. In addition, participants reported basic sociodemographic characteristics: gender, age, professional category and ethnicity. 


\section{Results}

Manipulation check. Participants in the social exclusion condition reported receiving fewer ball tosses and feeling more excluded than included participants. Furthermore, excluded participants reported experiencing lower feelings of belonging, self-esteem, control and meaningful existence than included participants (see Table 2).

We formally assessed the effect of the social exclusion manipulation on perception of exclusion among those who did $(n=54)$ and did not $(n=240)$ have previous experience of playing the Cyberball game. We conducted a MANOVA with all of the checking measures of the post-experiment questionnaire and after the debriefing as dependent variables with experience and social exclusion as independent variables. The results of the multivariate tests showed a significant main effect of social exclusion via the Cyberball game in the expected direction, $F(7,284)=72.84, p<.001, \eta_{\mathrm{p}}{ }^{2}=.64$ (see Table 2 for the results of the betweensubjects effects). The main effect of having previous experience of the game on perception of exclusion was also significant, $F(7,284)=2.13, p=.041, \eta_{\mathrm{p}}{ }^{2}=.05$, but its interaction with the social exclusion manipulation was not, $F(7,284)<1$. Previous experience of Cyberball was therefore added to the subsequent analyses as a covariate ${ }^{4}$. After the debriefing, excluded participants reported feeling similar levels of mood and self-esteem to included participants.

<Insert Table 2 about here>

\footnotetext{
${ }^{4}$ We also conducted the analyses without a covariate. The analyses showed the same effect or absence of effect of social exclusion as reported in the analyses conducted with a covariate.
} 
Pre-publication version

SOCIAL EXCLUSION AND DECISION MAKING

Table 2

Effect of social exclusion on perception of exclusion and fundamental need, and post-briefing measures in Experiment 1.

\begin{tabular}{|c|c|c|c|c|}
\hline & Inclusion $(N=138)$ & Exclusion $(N=156)$ & Test & $\mathrm{ES}$ \\
\hline & $M(S D)$ & $M(S D)$ & $F(\mathrm{df} 1, \mathrm{df} 2)$ & \\
\hline Perception of exclusi & & & $F(1,293)$ & $\eta_{\mathrm{p}}^{2}$ \\
\hline Ball toss proportion & $32.17(11.13)$ & $9.49(9.87)$ & $216.28 *$ & 0.43 \\
\hline Feeling of exclusion & $1.59(0.88)$ & $4.40(0.98)$ & $399.61 *$ & 0.58 \\
\hline Fundamental needs & & & & \\
\hline Feeling of belonging & $3.89(0.75)$ & $1.91(0.93)$ & $245.75^{*}$ & 0.46 \\
\hline Self-esteem & $3.46(0.85)$ & $2.40(0.91)$ & $66.56^{*}$ & 0.19 \\
\hline Feeling of control & $2.95(0.74)$ & $1.60(0.72)$ & $147.00 *$ & 0.34 \\
\hline Meaningful existence & $3.75(0.70)$ & $2.12(1.01)$ & $154.35 *$ & 0.35 \\
\hline Mood & $1.55(0.97)$ & $0.98(1.12)$ & $13.66^{*}$ & 0.05 \\
\hline Post debriefing meas & ures & & $F(2,293)$ & $\eta_{p}^{2}$ \\
\hline Self-esteem 2 & $3.80(0.84)$ & $3.65(0.82)$ & 2.58 & .01 \\
\hline Mood 2 & $1.72(1.15)$ & $1.56(1.23)$ & 1.20 & $<.01$ \\
\hline
\end{tabular}

Note: ${ }^{*} p<.02$. Test: Inferential test, MANOVA; ES: Effect size.

Effect of social exclusion on cognitive reflection. Social exclusion did not affect participants' performance in the CRT, $M_{\text {Inclusion }}=1.38, S D 1.20, M_{\text {Exclusion }}=1.31, S D=1.12$, 


\section{SOCIAL EXCLUSION AND DECISION MAKING}

ANCOVA: $F(1,293)<1, \eta^{2}<.01$. We also tested our hypothesis with a Bayes factor analysis performed with JASP, using the BayesFactor package (Morey, Rouder, Jamil, \& Morey, 2015). This analytical procedure enabled us to quantify the strength of evidence supporting the null hypothesis (i.e., social exclusion does not affect CRT performance) and the alternative hypothesis (i.e., social exclusion affects CRT performance). The Bayes factor analysis ${ }^{5}$ dovetailed the ANCOVA, and used social exclusion as an independent variable and CRT performance as a dependent variable with Cyberball experience as a covariate (included as a nuisance term in both the null and the alternative models $)^{6}$. The results provided substantial evidence in favour of the null model against the social exclusion model by a factor of $\mathrm{BF}_{01}=7.15$. This means that the data we observed were 7 times more likely under the assumption that social exclusion does not affect CRT performance compared to the assumption that exclusion affects CRT performance.

\section{Correlation between social exclusion perception and CRT performance. A}

correlation analysis between exclusion perception variables and CRT performance showed no significant relationships, Pearson's $r$ varied from -.10 with mood to .08 , with life meaning (all $p s>.05)$.

Time spent on the task. Following the arguments that exclusion reduces deliberation and that deliberative thinking takes more time than intuitive responding (Ghazal et al., 2014), we expected that social exclusion would be related to a decrease in time spent on the task. However, this was not the case: excluded and included participants spent approximately the same amount of time on the tasks (around 40 seconds), $F(1,293)=0.02, \eta_{\mathrm{p}}{ }^{2}<.01$. The Bayes factor analysis of the effect, including prior experience of Cyberball as a nuisance term,

\footnotetext{
${ }^{5}$ All Bayesian analyses were conducted with the default prior of the BayesFactor of JASP.

${ }^{6} \mathrm{BF}_{01}$ is a ratio of the likelihood of observing the data given the null hypothesis relative to the likelihood of observing the data given the alternative hypothesis. $\mathrm{BF}_{01}$ higher than 1 is seen as evidence in support of the null hypothesis (from anecdotal to extreme) whereas $\mathrm{BF}_{01}$ values lower than 1 are seen as evidence in favour of the alternative hypothesis. $\mathrm{BF}_{10}$ is a ratio of the likelihood of observing the data given the alternative hypothesis relative to the likelihood of observing the data given the null hypothesis.
} 
Pre-publication version

\section{SOCIAL EXCLUSION AND DECISION MAKING}

provided substantial evidence in favour of the null model against the social exclusion model, $\mathrm{BF}_{01}=7.84$. This means that the data we observed were 7 times more likely under the assumption that social exclusion does not affect CRT time completion compared to the model assuming that it does.

\section{Discussion}

Consistent with the past literature (Gerber \& Wheeler, 2009), we found that being included or excluded in a ball-tossing game had a strong effect on how participants felt (e.g., lower self-esteem, lower feelings of control). However, experience of exclusion had no effect on participants' CRT scores. The results offer considerable support in favour of the null hypothesis.

\section{Experiment 2}

The goal of Experiment 2 was to test the effect of social exclusion on four judgment and decision-making tasks requiring deliberate reasoning (Oechssler et al., 2009).

\section{Method}

Participants. The study was powered to identify a medium effect in the analyses that we planned to use for the anchoring effect (between-subjects t-tests, $d=.50$ ). We planned to conduct our analysis on a sample of 102 participants. The sample size was adjusted upward (by $40 \%$ ) to account for data loss in the data-screening procedure. A total of 144 participants took part in the study.

Data screening. We followed the same screening procedures as for Experiment 1, excluding responses based on completion duration $(n=7)$, reported problems with Cyberball $(n=2)$, repeater participants in the same experiment $(n=0)$ and participants who took part in Experiment $1(n=5)$. In total, we excluded 17 participants. This left us with 127 participants (50\% female), whose ages ranged between 19 and $69(M=34.23, S D=11.09)$, which would enable the experiment to detect a small to medium effect size (Cohen's $d=0.44$ ). A 
Pre-publication version

\section{SOCIAL EXCLUSION AND DECISION MAKING}

sensitivity analysis showed that such a sample size would detect a small to medium effect for the conjunction and intertemporal choice tasks where we used a $\chi^{2}$ test $(\mathrm{w}=.28)$.

Materials and procedure. We followed the same procedure as in Experiment 1, except that instead of completing the CRT participants completed decision-making tasks. The tasks were presented on different pages and in a random order for each participant, except for the confidence task which was always presented last. The details of the wording of the tasks are listed in Appendix D.

The anchoring task. The task was taken from the work of Ariely, Loewenstein, and Prelec (2003). Participants were shown a picture of a wireless keyboard along with a brief description of it. They were then asked to type in the last two digits of their social security number. This number was used as an anchor. Subsequently they were asked to consider the number they just entered as the price of the keyboard and to ruminate on whether they would be willing to pay that price for the keyboard. Finally, participants stated the highest price they would be willing to pay for the keyboard (i.e., their willingness to pay for the product). The anchoring effect was measured by the absolute difference between the highest price given by participants and the anchor value. Hence, lower anchoring scores represented a stronger anchoring effect. For example, a participant with an anchor of 20 and a willingness to pay $\$ 10$ had an anchoring score of 10 , whereas a participant with an anchor of 80 and a willingness to pay $\$ 60$ had an anchoring score of 20 .

The conjunction task. The conjunction task was an adaptation of the "Bill" problem (Tversky \& Kahneman, 1983). Participants read a short vignette describing Bill as a stereotypical accountant (e.g., intelligent, very punctual, unimaginative). Then participants ranked three possible occupations for Bill from the most likely to the least likely. The three options were: Bill is an accountant, Bill is an accountant and plays in a rock band for a 
Pre-publication version

\section{SOCIAL EXCLUSION AND DECISION MAKING}

hobby, and Bill plays in a rock band for a hobby. Participants who estimated that the conjunction of two events was more likely than their single occurrence were incorrect. Hence, in this context, participants who estimated that Bill had a greater probability of being an accountant and playing in a rock band for a hobby than only being an accountant or only playing in a rock band were incorrect and their answers were coded as 0. Participants who estimated that Bill had a lower probability of being an accountant and playing in a rock band than being either of those things were correct and their answers were coded as 1 .

The intertemporal choice task. Participants were offered one of two hypothetical rewards: one immediate reward and a larger delayed one, following the standard discounting task (Frederick, Loewenstein, \& O'Donoghue, 2002). Participants chose between getting $\$ 1,000$ now and $\$ 1,010$ in a week.

The confidence task. Participants assessed whether they thought they gave the correct answer in the discounting and disjunction tasks. We derived a confidence score by subtracting the number of actual correct answers (0-2) from the self-reported number of correct answers (e.g., Ghazal et al., 2014; Juslin, 1994). No matter whether or not the participants' choice was the "correct" answer in the discounting task (the patient option), higher scores reflected more confident participants. When the reported number of correct answers was lower than the actual one, we gave participants a confidence score of 0 (only 2 participants had more correct answers than expected).

The Cyberball post-experiment questionnaire and debriefing. After playing the Cyberball game, and completing the judgment and decision-making tasks, participants completed the Cyberball post-experiment questionnaire and the self-esteem boosting exercise as per Experiment 1.

\section{Results}


Pre-publication version

\section{SOCIAL EXCLUSION AND DECISION MAKING}

Checking the effect of the exclusion manipulation. Excluded participants reported receiving fewer ball tosses and feeling more excluded than included participants (Appendix C). Further, excluded participants reported feeling a lower level of belonging, self-esteem, control and meaningful existence than included participants. As in Experiment 1, we formally assessed the effect of social exclusion and Cyberball experience $(n=36)$ on exclusion perceptions. The results of the multivariate tests showed a main effect of social exclusion on the perception of exclusion, $F(8,116)=22.84, p<.001, \eta_{\mathrm{p}}{ }^{2}=.61$. The between-subjects effects indicated that the manipulation affected all the checking measures (Appendix C). Previous experience of the game made a difference to the perception of exclusion, $F(8,116)$ $=2.06, p=.046, \eta_{\mathrm{p}}{ }^{2}=.12$, but did not interact with the social exclusion manipulation, $F(8$, $116)<1$. Previous experience with Cyberball was included as a covariate in the subsequent analyses. The debriefing and self-esteem boosting interventions were successful: the emotions and self-esteem levels reported by participants at the end of the questionnaire were not affected by the social exclusion manipulation.

Effect of social exclusion on anchoring. Participants exhibited the traditional anchoring effect as shown by the correlation between the anchor and the prices participants were willing to pay $(r=.26, p=.003)$. Table 3 shows the average anchoring score for excluded and included participants, with stronger anchoring for excluded participants. We tested the impact of social exclusion on the anchoring score in an ANCOVA with social exclusion as an independent variable, Cyberball experience as a covariate and the anchoring score as a dependent variable. The results showed that social exclusion did not result in stronger anchoring effects, $F(1,124)=1.08, p=.301, \eta_{\mathrm{p}}{ }^{2}=.01$. We conducted a Bayes factor analysis with social exclusion anchoring score as a dependent variable and Cyberball experience as a covariate. The results provided anecdotal evidence in support of the null 
Pre-publication version

\section{SOCIAL EXCLUSION AND DECISION MAKING}

hypothesis, showing that the data were 3 times more likely under the assumption that social exclusion did not have an impact on the anchoring effect, $\mathrm{BF}_{01}=3.19$.

$<$ Insert Table 3 about here>

Table 3

Effect of social exclusion on performance in the anchoring, conjunction, intertemporal choice and confidence tasks in Experiment 2.

\begin{tabular}{lcc}
\hline JDM task & Inclusion & Exclusion \\
& $(N=65)$ & $(N=62)$ \\
\hline Anchoring score (lower scores show more anchoring) & $19.68(30.28)$ & $13.68(30.23)$ \\
Conjunction fallacy & $69 \%$ & $71 \%$ \\
Preference for immediate and smaller rewards & $75 \%$ & $58 \%$ \\
Confidence & $1.37(0.60)$ & $1.19(0.67)$ \\
\hline
\end{tabular}

Effect of social exclusion on the conjunction fallacy. Most participants committed the conjunction fallacy and believed that Bill was more likely to be an accountant and to play in a rock band than to be an accountant or to play in a rock band. However, excluded participants performed as well as included participants (see Table 3). To assess the effect of social exclusion while controlling for the effect of having experienced the Cyberball game before, we conducted a binary logistic regression where social exclusion and Cyberball experience were entered as predictor variables, along with their interaction. The regression model was not statistically significant, $\chi^{2}(3)=0.06, p=.996$ and explained less than $1 \%$ of the variance (Nagelkerke $R^{2}$ ). The summary of the model is shown in Table 3. The analysis showed that social exclusion did not impact the ability to judge probability conjunction. 
Pre-publication version

\section{SOCIAL EXCLUSION AND DECISION MAKING}

We conducted a Bayes factor analysis with social exclusion as an independent variable and conjunction score as a dependent variable. The results provided substantial evidence for the null hypothesis by showing that the data were almost five times more likely under the null hypothesis than under the assumption that social exclusion affected how many participants committed the conjunction fallacy, $\mathrm{BF}_{01}=4.88$.

<Insert Table 3 about here>

Table 3

Effect of social exclusion, Cyberball experience and their interaction on the frequency of conjunction fallacy and impatient choice in the intertemporal choice task in Experiment 2.

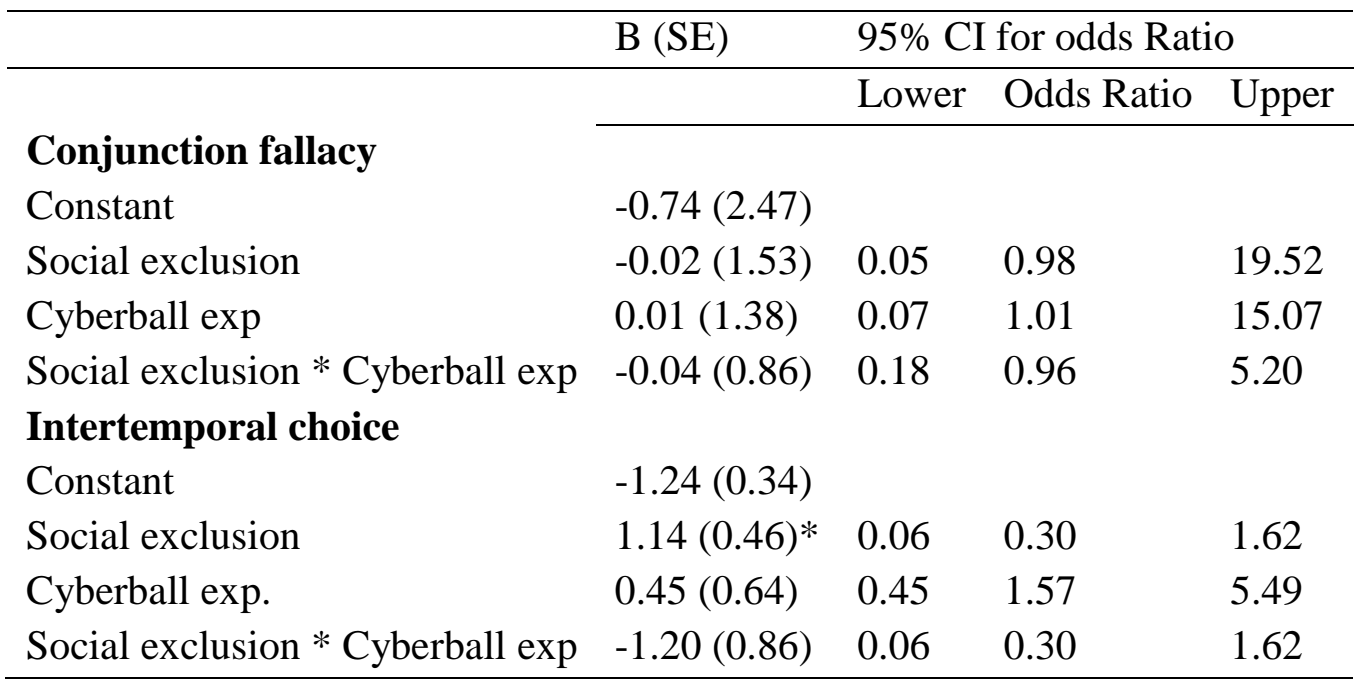

Note: $* p<.02$

Effect of social exclusion on intertemporal choice. Overall, the majority of participants $(67 \%)$ preferred the immediate and smaller reward $(\$ 1,000$ now vs. $\$ 1,010$ in a week). Excluded participants were more likely to be patient and select the larger reward than included participants. To assess the effect of social exclusion on intertemporal choice, while controlling for the effect of having experienced Cyberball before, we conducted a binary logistic regression with social exclusion and Cyberball experience as predictor variables, 
Pre-publication version

\section{SOCIAL EXCLUSION AND DECISION MAKING}

along with their interaction. The regression model (Table 3) was not statistically significant, $\chi^{2}(3, N=127)=6.58, p=.086$. The model explained around $7 \%$ of the variance in intertemporal choice (Nagelkerke $R^{2}$ ) and showed that social exclusion had a statistically significant effect on intertemporal choice. We conducted a Bayes factor for independent multinomial distribution with social exclusion as an independent variable and intertemporal choice as a dependent variable (without Cyberball experience as a covariate). The results provided anecdotal evidence for the alternative hypothesis. The data were almost twice more likely to occur under the alternative than under the null hypothesis, $\mathrm{BF}_{10}=1.72$.

Effect of exclusion on confidence. On average, participants believed that they were correct more times than they actually were by one answer out of three (see Table 3). Participants' confidence in their performance was similar among those who were excluded and included. We tested the impact of social exclusion on confidence in an ANCOVA with social exclusion as an independent variable, Cyberball experience as a covariate and confidence as a dependent variable. The results showed that social exclusion did not affect confidence, $F(1,124)=2.24, p=.137, \eta_{\mathrm{p}}{ }^{2}=.02$. The same analysis (including the covariate) was conducted with a Bayes factor. The results provided anecdotal evidence in support of the null hypothesis positing that social exclusion does not affect confidence, $\mathrm{BF}_{01}=1.94$.

\section{Correlation between social exclusion perception and decision-making}

performance. A non-parametric correlation analysis between the checking variables and the four decision-making performance variables merely showed two correlation coefficients that were statistically significant out of the 24 coefficients. There was a positive correlation between the feelings of control and confidence, $r=.18, p=.049$ and a negative correlation between feelings of control and the intertemporal choice performance, $r=-22, p=.015$. 
Pre-publication version

\section{SOCIAL EXCLUSION AND DECISION MAKING}

People with higher perceived control were more confident and chose the suboptimal impatient reward more often. Otherwise, $r$ varied from -.15 to .15 , with all $p \mathrm{~s}>.05$.

Time spent on the tasks. The overall time participants spent on the tasks was similar in the inclusion and the exclusion condition (around 80 seconds), $F(1,126)=0.99, p=.322$, $\eta_{\mathrm{p}}{ }^{2}=.01$. A Bayes factor analysis of the effect, including prior experience as a nuisance term, provided substantial evidence in favour of the null model against the social exclusion model by a factor of $\mathrm{BF}_{01}=3.32$. The data were more than 3 times more likely under the assumption that social exclusion does not affect the time spent on the tasks compared to the model assuming that it does.

\section{Discussion}

In Experiment 2, we compared judgments and decisions among those who were excluded and included in the game of Cyberball. Overall, the experience of rejection did not have an impact on participants' responses. Although classic judgment and decision-making fallacies were common in our sample, they were not more prevalent among the excluded individuals. This is in contrast to our predictions that social exclusion leads to impaired deliberative thinking. In the case of temporal discounting, the results showed a significant difference between the included and excluded participants. Excluded participants showed more patience and less discounting on average, which is inconsistent with the previous research showing that participants in an exclusion condition were less patient than those in the included condition (Twenge et al., 2002a).

\section{Experiment 3}

Given that the results of Experiment 2 were inconsistent with our predictions, Experiment 3 aimed to replicate Experiment 2 with a larger number of tasks and a larger sample. 
Pre-publication version

\section{SOCIAL EXCLUSION AND DECISION MAKING}

Furthermore, to identify whether exclusion or inclusion explains any changes in judgments and decision-making, Experiment 3 included a control condition, where participants only watched players passing the ball to each other.

\section{Method}

Participants. The samples for Experiments 1 and 2 were chosen based on the findings of Baumeister et al. (2002), showing strong effects of social exclusion on cognitive ability tasks. Given that we did not find strong effects in Experiments 1 and 2, we based our sample size selection on detecting a small effect size. The study was powered to identify the only effect observed in Experiment 2 (a small effect of social exclusion on intertemporal choice). Building on the power calculation for a 2 (anchor) x 3 (social exclusion) between-subjects design, the aim of Experiment 3 was to include 500 participants.

Data screening. A total of 545 participants completed the survey. We followed the same screening procedure as for Experiments 1 and 2. Based on completion duration $(n=$ 24), reported problems with Cyberball $(n=9)$, repeater participants in the same experiment $(n$ $=0)$ and participants who took part in Experiments 1 or $2(n=28)$, we excluded a total of 62 participants. Our final sample size $(N=484)$ resulted in a power that would enable the experiment to detect a small effect size in a mean comparison analysis with three groups and a covariate $($ Cohen's $f=0.15)$. A sensitivity analysis showed that such a sample size would detect a small to medium effect for the conjunction and intertemporal choice tasks $(\mathrm{w}=.28)$. The age range of the final sample (50\% female) was between 18 and $81(M=35.75, S D=$ 12.83). 
Pre-publication version

\section{SOCIAL EXCLUSION AND DECISION MAKING}

Design. Participants were randomly allocated to one of three social conditions: included, excluded or control. In the control condition, participants watched a Cyberball game in which the ball was tossed randomly by the three players.

Materials and procedure. The materials and procedure were the same as in Experiment 1, except for the decision-making tasks, which are described below (and presented in Appendix E).

Anchoring block. We used four of the eight items used in Strack and Mussweiller (1997), Study 3: the temperature in Antarctica, the birth year of Leonardo da Vinci, the year of Einstein's first visit to the US and the age of Mahatma Gandhi when he died. For each item, participants answered both a comparative and an absolute question (presented on the same page). In the comparative judgment question, participants assessed whether the correct answer was lower or higher than an anchor value provided, which was either lower or higher than the correct value (Strack \& Mussweiller, 1997). The instructions specified that the anchor value was randomly selected to minimise the informativeness of the anchor value (Jacowitz \& Kahneman, 1995). For the absolute question, participants filled in a blank space with their answer (e.g., the year that Einstein visited the US for the first time).

Participants read one of two versions of the anchoring task. Version 1 featured Antarctica and da Vinci with a low anchor and Einstein and Gandhi with a high one. Version 2 featured Antarctica and da Vinci with a high anchor and Einstein and Gandhi with a low one. In both cases the order of presentation of the items was randomised for each participant. We were therefore able to compute a low and a high anchoring score for each participant. The low anchor score was the average normalised score for the two questions which were associated with a low anchor and the high anchor score was the average normalised score for 
Pre-publication version

\section{SOCIAL EXCLUSION AND DECISION MAKING}

the two questions which were associated with a high anchor. The anchoring effect was assessed by comparing the low and the high anchor normalised scores.

Intertemporal choice block. We used the question from Experiment 2 and three additional ones taken from Frederick (items c, $d$ and e; 2005). In all the items participants were offered the choice of two rewards given at two different times where the delayed reward was always larger than the immediate one. For each pair, participants' responses were coded as 1 when they chose the delayed but higher reward and as 0 when they chose the immediate and smaller reward. The four items comprised a scale that reached a satisfactory reliability (Cronbach's alpha $=.65)$. We computed a discounting score by summing the participants' response in the four discounting items.

Confidence block. To assess confidence, we asked participants how many times they provided a correct answer in the discounting and anchoring tasks. Participants assessed the number of correct answers in the last eight tasks. (i.e., in the last eight tasks, I provided correct answers). A confidence score was computed based on the number of actual correct answers minus the number of anticipated correct answers. Confidence scores therefore ranged from 0 to 6. Participants who believed that they would provide fewer correct answers than they actually did received a score of 0 (7\% of the participants).

\section{Results}

Checking the effect of the manipulation. Excluded participants reported receiving fewer ball tosses and feeling more excluded than included participants. Furthermore, excluded participants reported feeling a lower level of belonging, self-esteem, control and meaningful existence than included participants (see Appendix F). Out of the 484 participants, 67 reported having played Cyberball in the past. The social exclusion perception 
Pre-publication version

\section{SOCIAL EXCLUSION AND DECISION MAKING}

questions focusing on ball toss proportion, feelings of exclusion and belonging were only asked of participants in the experimental conditions (inclusion and exclusion); the other questions were asked in the control condition. Therefore we ran two variance analyses with Cyberball experience as a covariate. The first MANCOVA compared the inclusion and exclusion conditions for ball toss proportion, feelings of exclusion, feelings of belonging and the post self-esteem intervention measures: self-esteem 2 and mood 2 . The second MANCOVA compared the exclusion, inclusion and the control group for self-esteem, feelings of control, meaningful existence and mood. The results showed that the social exclusion manipulation was successful. There was a significant main effect of social exclusion manipulation on social exclusion perception in the case of both analyses, $F(5,316)$ $=9.07, p<.001, \eta_{\mathrm{p}}{ }^{2}=.13$ and $F(8,952=5.07), p<.001, \eta_{\mathrm{p}}{ }^{2}=.04$ (see Appendix $\mathrm{F}$ for between-subjects effects on individual variables). The results of the multivariate tests in both analyses showed no significant main effect of Cyberball experience, $F(5,119)=1.27, \mathrm{p}=\eta_{\mathrm{p}}{ }^{2}$ $=.02$ and $F(4,475)<1, \eta_{\mathrm{p}}^{2}=.01$. However, the interaction was significant for the second analysis, $F(8,952)=2.22, p=.024, \eta_{\mathrm{p}}{ }^{2}=.02$. Cyberball experience was added as a covariate in the subsequent analyses. The debriefing and the self-esteem boosting intervention were successful. Emotions and self-esteem reported by participants at the end of the questionnaire were not affected by the social exclusion manipulation.

Effect of social exclusion on anchoring. As depicted in Table 4, participants exhibited the classic anchoring effect. They provided lower response values in the low anchor condition than in the high anchor condition, $t(483)=8.11, p<.001, d=.74$. To assess the effect of social exclusion we ran a within-subjects analysis of variance with anchor magnitudes (low vs. high) as a within-subjects independent variable, social exclusion as a between-subjects independent variable, anchoring scores as dependent variables and Cyberball experience as a 
Pre-publication version

\section{SOCIAL EXCLUSION AND DECISION MAKING}

covariate. The effect of the magnitude of the anchor was not moderated by the social exclusion manipulation, as shown by the non-statistically significant interaction effect, $F(2$, $378)<1, \eta_{p}^{2}<.01$. We conducted a Bayes factor analysis comparing two models. First, a null model including social exclusion (included, excluded, control) and anchor (low vs. high) with Cyberball experience as a nuisance term. Second, an interaction model including the same terms along with the interaction term of social exclusion factor (included, excluded, control) and anchor factor (low vs. high). The interaction model tested whether social exclusion moderated the effect of an anchor on the estimates provided by participants. The comparison between the two models provided support for the null model, therefore supporting that social exclusion did not moderate the anchoring effect, $\mathrm{BF}_{01}=36.39$.

<Insert Table 4 about here >

Table 4

Effect of social exclusion on mean decision-making performance in Experiment 3 (SD).

\begin{tabular}{lccc}
\hline & Inclusion & Exclusion & Control \\
& $(N=162)$ & $(N=162)$ & $(N=160)$ \\
\hline Anchoring low & $-0.17(0.42)$ & $-0.15(0.58)$ & $-0.13(0.54)$ \\
Anchoring high & $0.19(0.47)$ & $0.11(0.50)$ & $0.21(1.29)$ \\
Average number of delayed and higher rewards & $1.55(1.40)$ & $1.42(1.30)$ & $1.69(1.41)$ \\
(out of 4) & & & \\
Confidence (-6 to 6) & $2.06(1.74)$ & $2.08(1.84)$ & $1.77(1.73)$
\end{tabular}

Note: For the anchoring scores, scores closer to 0 indicated smaller anchoring effects, whereas scores further from 0 in the negative or positive show an effect of anchoring. For the confidence score, positive values indicate over-confidence whereas negative values indicate under-confidence. 
Pre-publication version

\section{SOCIAL EXCLUSION AND DECISION MAKING}

Effect of social exclusion on intertemporal choice. Participants generally discounted future rewards and chose the immediate option with the smaller reward in one or two of the four choices on average (see Table 4). Excluded participants chose the impatient option as often as the included or control participants. To assess the effect of social exclusion on intertemporal choice, we ran a between-subjects analysis of variance with social exclusion as a between-subjects independent variable, intertemporal choice scores as dependent variables and Cyberball experience as a covariate. Social exclusion did not affect people's decision in the intertemporal choice task, $F(2,483)=1.46, p=.233, \eta^{2} \mathrm{p}=.01$. Cyberball experience did not reveal a significant main effect or an interaction effect with the social exclusion manipulation, $F(2,483)<1, \eta_{\mathrm{p}}^{2}<.01, F(2,483)=1.48, p=.230, \eta_{\mathrm{p}}^{2}=.01$, respectively. We conducted a Bayesian factor analysis with social exclusion as the independent variable and intertemporal choice score as the dependent variable, along with Cyberball experience as a nuisance covariate term. The analysis provided strong evidence in favour of the null hypothesis, which posited that social exclusion does not affect intertemporal choice, $\mathrm{BF}_{01}=$ 11.47.

Effect of social exclusion on confidence. Participants were quite confident in their performance: They estimated that they would give more correct answers than they actually did (see Table 4). The average performance was to provide 1.70 correct answers out of 8 (SD $=2.21)$, but participants believed that they had provided 3.60 correct answers $(S D=2.06)$, $t(483)=-26.60, p<.001, d=-2.42$. To assess the effect of social exclusion we ran a between-subjects analysis of covariance with social exclusion as an independent variable, confidence as a dependent variable and Cyberball experience as a covariate. Participants in the control condition were less confident than participants in the inclusion or the exclusion condition, $F(2,483)=3.62, p=.027, \eta_{\mathrm{p}}{ }^{2}=.02$. There was no significant main effect of 
Pre-publication version

\section{SOCIAL EXCLUSION AND DECISION MAKING}

Cyberball experience but there was a significant interaction with the social condition to predict confidence, $F(2,483)=3.47, p=.032, \eta^{2} \mathrm{p}=.01$. Participants who had experienced Cyberball before were more confident in the inclusion condition than in the exclusion and control conditions, whereas participants who were unfamiliar with Cyberball showed the highest confidence in the exclusion condition, and the lowest in the control condition. A similar analysis was conducted using a Bayes factor analysis with Cyberball experience included as a nuisance covariate term. The results showed strong evidence to support the null hypothesis against the hypothesis that social exclusion had an impact on confidence, $\mathrm{BF}_{01}=$ 11.54 .

\section{Correlation between social exclusion perception and decision-making}

performance. A non-parametric correlation analysis was carried out between the checking variables and the decision-making performance variables. All correlations were weak and varied between $r=-.09$ and .08 , all $p \mathrm{~s}<.05$.

Time spent on the tasks. The overall time participants spent on the tasks was similar in the inclusion, exclusion and control conditions (around 95 seconds), $F(2,483)=1.34, p=$ $.263, \eta_{\mathrm{p}}{ }^{2}<.01$. A Bayes factor analysis of the effect, including prior experience as a nuisance term, provided substantial evidence in favour of the null model against the social exclusion model by a factor of $\mathrm{BF}_{01}=6.66$. The data we observed were almost 7 times more likely under the assumption that social exclusion does not affect time spent on solving the tasks compared to the model assuming that it does.

\section{Evidence synthesis: The null effect of social exclusion on rational thinking}

Finally, to estimate the overall impact of social exclusion on judgment and decisionmaking performance, we conducted an internal small-scale meta-analysis (Cumming, 2014). We entered all nine comparisons accumulated across the three experiments and accounted for 
Pre-publication version

\section{SOCIAL EXCLUSION AND DECISION MAKING}

its nested structure using a multi-level random effect model (Viechtbauer, 2010). For the purpose of this meta-analysis, the scores were entered in such a way that higher scores always indicated bias/worse performance (i.e., diverging from rational thinking). We used the variables as they are depicted in the tables when higher scores indicated more biases, but we reverse scored the variables for which higher scores indicated fewer biases. (We used the number of incorrect CRT responses, we subtracted the anchoring score of Experiment 2 from 100 (highest value) and finally we used the number of immediate and lower rewards for the intertemporal choice measure of Experiment 3). We then calculated the standardised effect size between included and excluded participants. (Only in Experiment 3 were these comparisons taken into account). Hence, an overall negative effect indicated a negative effect of social exclusion on decision-making performance, whereas an overall positive effect indicated a positive effect of social exclusion on performance. We observed that the effects were close to zero and occurred on both sides (see Figure 1): positive as well as negative and never statistically significantly different from zero with one exception (discounting Experiment 2). We did not observe a substantial variation in the outcomes between comparisons, $Q(8)=10.94, p=.206$. Critically, the overall effect was close to $0, g=0.02$, $95 \% \mathrm{CI}[-0.06,0.11]$ and was not statistically significant, $z=0.54, p=.590$. Thus, the metaanalysis clearly indicated that social exclusion did not affect judgments or choices: Participants who were socially excluded in the Cyberball game did not make worse (or better) judgments and choices.

<insert Figure 1 about here> 
Pre-publication version

SOCIAL EXCLUSION AND DECISION MAKING

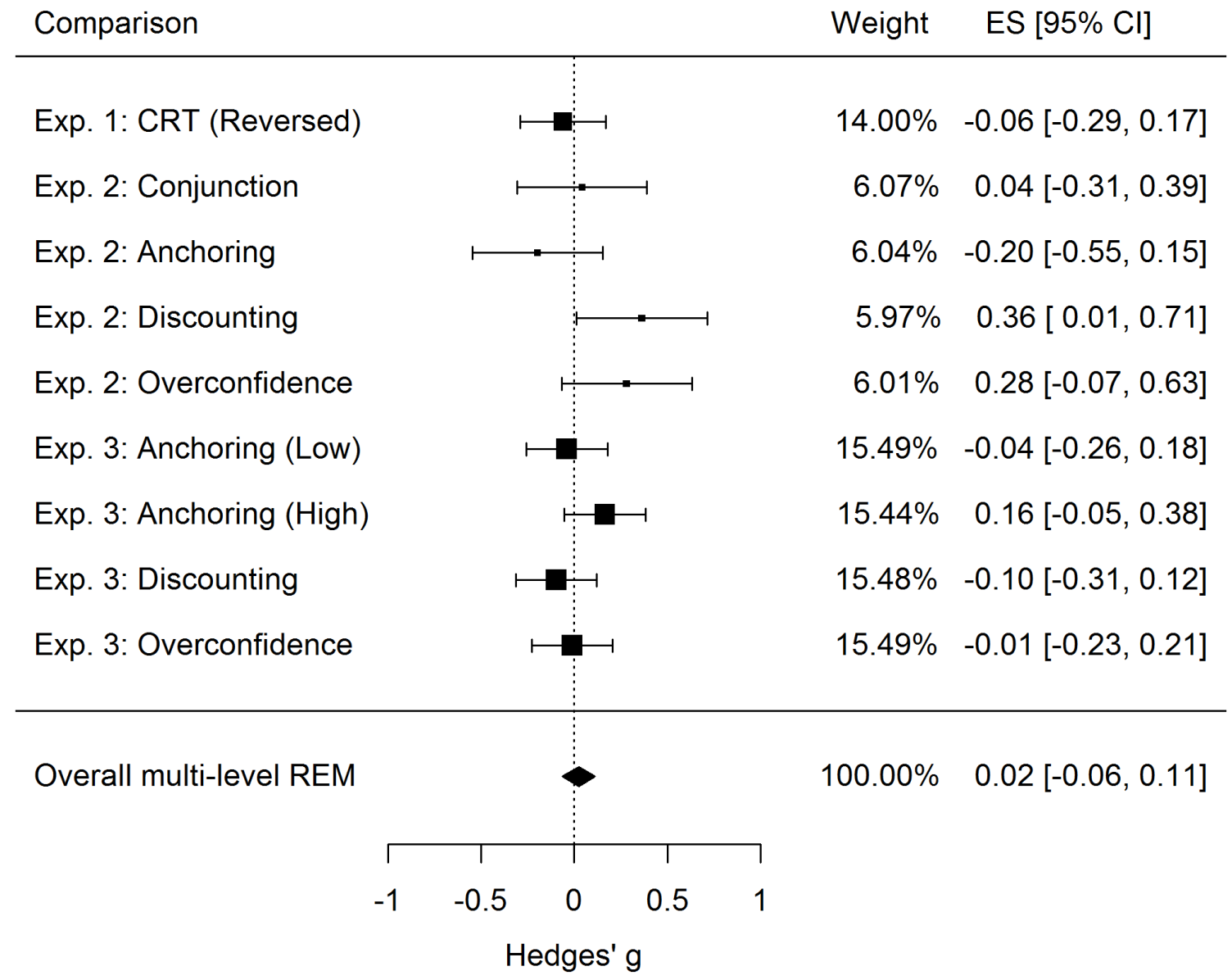

Figure 1: Effect of social exclusion (vs. social inclusion) on rational thinking (higher scores indicate more bias/less rational thinking) across the three experiments reported here (a multilevel random effect).

\section{General Discussion}

The results of a growing body of research in social psychology posit that social rejection (either anticipated or experienced) affects people's ability to engage in deliberate reasoning. Support for this association comes from studies in which socially excluded individuals (or those who anticipate or describe being rejected) perform considerably worse in a range of cognitively demanding tasks when compared to participants who are not 
Pre-publication version

\section{SOCIAL EXCLUSION AND DECISION MAKING}

excluded (Baumeister et al., 2005; Baumeister et al., 2002). Building on these efforts, we tested whether experiencing rejection in a Cyberball game (Zadro et al., 2004) influenced people's judgments and decisions. We tested the hypothesis in three experiments focusing on five different judgment and decision-making tasks.

In Experiment 1, we compared the performance of excluded and included individuals in the Cognitive Reflection Task (Frederick, 2005), in which participants must suppress intuitive responses to find a correct solution to three numerical reasoning puzzles. Excluded participants performed similarly to included participants. Consistent with this result, and in contrast with our hypothesis, Experiments 2 and 3 showed that excluded individuals were unlikely to be influenced by meaningless anchors, did not discount future rewards more, did not commit the conjunction fallacy more often, and did not exhibit higher confidence in their judgments and choices. A meta-analysis provided evidence that the lack of effect did not occur due to an insufficient sample size, given that even when we maximised the power in our experiments using meta-analytical techniques, the overall effect was virtually zero. Nonetheless, in all these experiments we found that exclusion had the expected impact on participants' basic psychological needs - rejected participants reported lower feelings of belonging and lower feelings of control, meaningful existence and self-esteem.

\section{All alone, but not bad decision-makers}

Overall, our null findings contrast with the results showing the effect of social exclusion on cognitive functioning (Baumeister et al., 2005; Hawes et al., 2012; Twenge, Catanese, \& Baumeister, 2002b). Social exclusion was indeed connected with decrements in a range of cognitive processes required to achieve good decision-making, such as intelligence and memory (Baumeister et al., 2002), inhibition (Baumeister \& DeWall, 2005; Baumeister 
Pre-publication version

\section{SOCIAL EXCLUSION AND DECISION MAKING}

et al., 2005) and the ability to cope with inconsistent information (Greitemeyer, Fischer, \& Kastenmüller, 2012).

We derived the deliberation impairment hypothesis from previous empirical work showing that social exclusion impairs deliberate reasoning and a comprehensive theoretical account assuming that deliberate reasoning influences people's judgments and choice. Within this framework, the threat to one's belongingness can be "disorienting" (pp. 4, Baumeister \& DeWall, 2005), leading to decrements in cognitive processing and self-regulation. Our results do not support the hypothesis that the experience of social exclusion in the Cyberball game would dampen people's ability to make judgments and decisions requiring analytical thinking. However, it remains possible that other forms of social exclusion manipulation (e.g., the prospect of a future alone, reminiscing about past experiences of social exclusion) would lead to a decrement in people's performance in such tasks. Nonetheless, our findings show that, at least in the context of the Cyberball manipulation, the impact of exclusion does not dampen the cognitive functioning necessary to respond in complex judgment and decision-making tasks. This discrepancy challenges the assumption that social exclusion impairs people's cognition and therefore requires further attention to better understand the complex dynamics of social rejection.

\section{How could social exclusion impair intelligence but not analytical thinking and decision- making?}

A number of methodological differences might explain the discrepancy between prior research showing a big effect of social exclusion on intelligence, memory and inhibition (all required to make good decisions), and our results showing that social exclusion does not impair decision-making quality. With regard to the former, it is plausible that our manipulation was not appropriate for lowering people's logical and systematic thoughts. 
Pre-publication version

\section{SOCIAL EXCLUSION AND DECISION MAKING}

Although previous work used a wide range of manipulations to induce feelings of exclusion, (Baumeister et al., 2002, 2005) manipulated social exclusion through an induced anticipated social exclusion. The negative prospect of being alone in the future could take more cognitive resources away from tasks requiring active deliberation than the live experience of social rejection in an online game. However, such an explanation for the discrepancy seems unlikely. Both manipulations have been used interchangeable in prior research studying the effects of rejection on socio-cognitive processes and have shown consistent effects (Baumeister et al., 2005; Williams, Cheung, \& Choi, 2000). For example, the prospect of living a future alone led to lower performance in a memory test (Baumeister et al., 2002) and consistently, the exclusion through the Cyberball game led to lower performance in a memory task (Xu et al., 2017), or in tasks measuring related constructs such as attention and intrinsic motivation (Lustenberger \& Jagacinski, 2010). Yet it is true that in our version of the task we did not assert that the Cyberball players were "real" players, whereas Xu et al. (2017) and Lustenberger and Jagacinski (2010) did. It is possible that participants did not demonstrate a decrement in decision-making performance because they believed they were playing with a computer. However, this possibility is weakened by the fact that past work involving Cyberball has demonstrated similar effects on feelings of exclusion and fundamental needs when participants were informed that they played with a computeranimated player instead of a real person (Zadro et al., 2004).

A final possibility to account for the null effect of the Cyberball exclusion manipulation is that the effect of the manipulation did not last long enough to impact deliberation in the tasks provided. The Williams' model of social exclusion (2009) maps the effect of social exclusion over time and suggests that social exclusion initially has a reflexive effect - and subsequently a reflective one. The model further suggests that it is during the first reflexive 
Pre-publication version

\section{SOCIAL EXCLUSION AND DECISION MAKING}

stage that social exclusion would dampen cognitive capacities. This hints at the possibility that the reflexive effect of social exclusion did not last long enough to affect decision-making performance. However, past work using Cyberball as a form of social exclusion manipulation had an effect in tasks that lasted longer than the present ones because they involved many trials (Buelow \& Wirth, 2017) or were delayed (Buelow et al., 2015).

Finally, participants systematically reported experiencing a lowered feeling of belonging in the exclusion condition, which is arguably the underlying mechanism leading to an impairment of cognitive abilities (Baumeister \& DeWall, 2005). Yet, we did not find any correlation between feelings of exclusion or fundamental needs and participants' performance in judgments and decision-making.

The possibility that our manipulation did not work is further weakened by the fact that, in past research, Cyberball was effective in affecting self-reported perceptions of social exclusion (Van Beest, Williams, \& Van Dijk, 2011; Walasek et al., 2015; Williams \& Jarvis, 2006; Zadro et al., 2004) and had an impact on relevant brain activity (Eisenberger, Lieberman, \& Williams, 2003; Preller et al., 2016) and behaviours (Lustenberger \& Jagacinski, 2010; Warburton, Williams, \& Cairns, 2006). In our studies, despite the significant and robust effect of a lowered need for belonging, we observed no differences in performance in the judgment and decision-making tasks.

Finally, our results could be attributed to the choice of tasks, which may not have been appropriate to reflect the effect of diminished ability to deliberate and think logically. We argue that this seems rather unlikely given the converging correlational and causal evidence between the judgments and decision-making in the tasks studied here and deliberative thinking (Bargh, 1994; Benjamin, Brown, \& Shapiro, 2013; Cacioppo \& Petty, 
Pre-publication version

\section{SOCIAL EXCLUSION AND DECISION MAKING}

1982; Dewberry et al., 2013; Epstein et al., 1996; Juanchich et al., 2016; Shiloh, Salton, \& Sharabi, 2002; Stanovich \& West, 2000; Toplak et al., 2014; Tversky \& Kahneman, 1974).

In conclusion, our findings do not show that social rejection impairs judgments and decisions. Despite the fact that these processes require active deliberation, rejected individuals performed as well as included participants. Compared with previous work, our results provide a less gloomy picture of the effects of social rejection on cognitive processing and logical thinking. 
Pre-publication version

SOCIAL EXCLUSION AND DECISION MAKING

\section{References}

Albaity, M., Rahman, M., \& Shahidul, I. (2014). Cognitive reflection test and behavioral biases in Malaysia. 149-151.

Alos-Ferrer, C., \& Hugelschafer, S. (2012). Faith in intuition and behavioral biases. Journal of Economic Behavior \& Organization, 84, 182-192.

Ariely, D., Loewenstein, G., \& Prelec, D. (2003). Coherent arbitrariness: Stable demand curves without stable preferences. Quarterly Journal of Economics, 118, 73-105. doi: $10.1162 / 00335530360535153$

Arkes, H. R., Gigerenzer, G., \& Hertwig, R. (2016). How bad is incoherence? Decision, 2039.

Bargh, J. (1994). The four horsemen of automaticity: Awareness, intention, efficiency. In R.

S. Wyer, Jr. \& T. K. Srull (Eds.), Handbook of social cognition: Basic processes; Applications, . Hillsdale, NJ, US: Lawrence Erlbaum.

Baumeister, R. F., \& DeWall, C. N. (2005). The inner dimension of social exclusion: Intelligent thought and self-regulation among rejected persons. In K. D. Williams, J. P. Forgas \& W. von Hippel (Eds.), The social outcast: Ostracism, social exclusion, rejection, and bullying (pp. 53-73). New York, NY, US: Psychology Press.

Baumeister, R. F., DeWall, C. N., Ciarocco, N. J., \& Twenge, J. M. (2005). Social Exclusion Impairs Self-Regulation. Journal of Personality and Social Psychology, 88, 589-604. doi: http://dx.doi.org/10.1037/0022-3514.88.4.589

Baumeister, R. F., Twenge, J. M., \& Nuss, C. K. (2002). Effects of Social Exclusion on Cognitive Processes: Anticipated Aloneness Reduces Intelligent Thought. Journal of Personality and Social Psychology, 83, 817-827-817-827. doi:

http://dx.doi.org/10.1037//0022-3514.83.4.817 
Pre-publication version

\section{SOCIAL EXCLUSION AND DECISION MAKING}

Benjamin, D. J., Brown, S. A., \& Shapiro, J. M. (2013). Who is 'behavioral'? Cognitive ability and anomalous preferences. Journal of the European Economic Association, 11, 1231-1255. doi: 10.1111/jeea.12055

Brand, M., Fujiwara, E., Borsutzky, S., Kalbe, E., Kessler, J., \& Markowitsch, H. J. (2005). Decision-making deficits of korsakoff patients in a new gambling task with explicit rules: associations with executive functions. Neuropsychology, 19, 267-277. doi: 10.1037/0894-4105.19.3.267

Brand, M., Recknor, E. C., Grabenhorst, F., \& Bechara, A. (2007). Decisions under ambiguity and decisions under risk: correlations with executive functions and comparisons of two different gambling tasks with implicit and explicit rules. J Clin Exp Neuropsychol, 29, 86-99. doi: 10.1080/13803390500507196

Bruine de Bruin, W., Parker, A. M., \& Fischhoff, B. (2007). Individual Differences in Adult Decision-Making Competence. Journal of Personality and Social Psychology, 92, 5 , 938-956. doi: http://dx.doi.org/10.1037/0022-3514.92.5.938

Buelow, M. T., Okdie, B. M., Brunell, A. B., \& Trost, Z. (2015). Stuck in a moment and you cannot get out of it: The lingering effects of ostracism on cognition and satisfaction of basic needs. Personality and Individual Differences, 76, 39-43. doi: https://doi.org/10.1016/j.paid.2014.11.051

Buelow, M. T., \& Wirth, J. H. (2017). Decisions in the face of known risks: Ostracism increases risky decision-making. Journal of Experimental Social Psychology, 69, 210217. doi: https://doi.org/10.1016/j.jesp.2016.07.006

Buhs, E. S., Ladd, G. W., \& Herald, S. L. (2006). Peer exclusion and victimization: Processes that mediate the relation between peer group rejection and children's classroom engagement and achievement? Journal of educational psychology, 98, 1. 
Pre-publication version

\section{SOCIAL EXCLUSION AND DECISION MAKING}

Cacioppo, J. T., \& Petty, R. E. (1982). The need for cognition. Journal of Personality and Social Psychology, 42, 116-131. doi: 10.1037/0022-3514.42.1.116

Campitelli, G., \& Labollita, M. (2010). Correlations of cognitive reflection with judgments and choices. Judgment and Decision Making, 5, 182-191.

Chen, Z., Williams, K. D., Fitness, J., \& Newton, N. C. (2008). When hurt will not heal: exploring the capacity to relive social and physical pain. Psychol Sci, 19, 789-795. doi: 10.1111/j.1467-9280.2008.02158.x

Cumming, G. (2014). The New Statistics. Psychological Science, 25, 7-29. doi: doi:10.1177/0956797613504966

DeWall, C. N., \& Bushman, B. J. (2011). Social Acceptance and Rejection: The Sweet and the Bitter. Current Directions in Psychological Science, 20, 256-260. doi: $10.1177 / 0963721411417545$

Dewberry, C., Juanchich, M., \& Narendran, S. (2013). Decision-making competence in everyday life: The roles of general cognitive styles, decision-making styles and personality. Personality and Individual Differences, 55, 783-788. doi: 10.1016/j.paid.2013.06.012

Eisenberger, N. I., Lieberman, M. D., \& Williams, K. D. (2003). Does Rejection Hurt? An fMRI Study of Social Exclusion. Science, 302, 290-292.

Epstein, S., Pacini, R., Denes-Raj, V., \& Heier, H. (1996). Individual Differences in IntuitiveExperiential and Analytical-Rational Thinking Styles. Journal of Personality and Social Psychology, 71, 390-405. doi: 10.1037/0022-3514.71.2.390

Evans, J. S. B. T. (2008). Dual-Processing Accounts of Reasoning, Judgment, and Social Cognition. Annual Review of Psychology, 59, 255-278. doi:

10.1146/annurev.psych.59.103006.093629 
Pre-publication version

\section{SOCIAL EXCLUSION AND DECISION MAKING}

Frederick, S. (2005). Cognitive Reflection and Decision Making. Journal of Economic Perspectives, 19, 25-42. doi: 10.1257/089533005775196732

Frederick, S., Loewenstein, G., \& O'Donoghue, T. (2002). Time discounting and time preference: A critical review. Journal of Economic Literature, 40, 351-401-351-401. doi: $10.1257 / 002205102320161311$

Gal, P., Mrva, M., \& Gajdosova, Z. (2014). The cognitive reflection test and the propensity to use heuristics in decision making. . Comenius Management Review., 8, 29-40.

Ghazal, S., Cokely, E. T., \& Garcia-Retamero, R. (2014). Predicting biases in very highly educated samples: Numeracy and metacognition. Judgment and Decision Making, 9, $15-34$

Gilovich, T., Griffin, D. W., \& Kahneman, D. (2002). Heuristics and biases: The psychology of intuitive judgement: NewYork: Cambridge University Press.

Greitemeyer, T., Fischer, P., \& Kastenmüller, A. (2012). The effects of social exclusion on confirmatory information processing. European Journal of Social Psychology, 42, 462-469. doi: 10.1002/ejsp.1851

Hawes, D. J., Zadro, L., Fink, E., Richardson, R., O'Moore, K., Griffiths, B., et al. (2012). The effects of peer ostracism on children's cognitive processes. European Journal of Developmental Psychology, 9, 599-613. doi: 10.1080/17405629.2011.638815

Hoppe, E. I., \& Kusterer, D. J. (2011). Behavioral biases and cognitive reflection. Economics Letters, 110, 97-100.

Jacowitz, K. E., \& Kahneman, D. (1995). Measures of Anchoring in Estimation Tasks. Personality and Social Psychology Bulletin, 21, 1161-1166. doi: http://dx.doi.org/10.1177/01461672952111004

Janda, L. (1996). The psychologist's book of self-tests. New York, NY: Berkley. 
Pre-publication version

\section{SOCIAL EXCLUSION AND DECISION MAKING}

Juanchich, M., Dewberry, C., Sirota, M., \& Narendran, S. (2016). Cognitive reflection predicts real-life decision outcomes, but not over and above personality and decisionmaking styles. Journal of behavioral decision-making. doi: http://dx.doi.org/10.1002/bdm.1875

Juslin, P. (1994). The overconfidence phenomenon as a consequence of informal experimenter-guided selection of items. Organizational Behavior and Human Decision Processes, 57, 226-246-226-246. doi: http://dx.doi.org/10.1006/obhd.1994.1013

Kahneman, D., \& Frederick, S. (2005). A model of heuristic judgment. The Cambridge handbook of thinking and reasoning, 267-293.

Kahneman, D., Knetsch, J. L., \& Thaler, R. H. (1991). Anomalies: The endowment effect, loss aversion, and status quo bias. The journal of economic perspectives, 5, 193-206. doi: 10.1257/jep.5.1.193

Keren, G., \& Teigen, K. H. (2004). Yet another look at the heuristics and biases approach. In D. J. Koehler \& N. Harvey (Eds.), (pp. 89-109): Oxford: Blackwell Publishing Ltd.

Lejuez, C. W., Read, J. P., Kahler, C. W., Richards, J. B., Ramsey, S. E., Gregory, L. S., et al. (2002). Evaluation of a Behavioral Measure of Risk Taking: The Balloon Analogue Risk Task (BART). Journal of Experimental Psychology: Applied, 8, 75--75- 84. doi: http://dx.doi.org/10.1037//1076-898X.8.2.75

Liberali, J. M., Reyna, V. F., Furlan, S., Stein, L. M., \& Pardo, S. T. (2012). Individual Differences in Numeracy and Cognitive Reflection, with Implications for Biases and Fallacies in Probability Judgment. Journal of Behavioral Decision Making, 25, 361381-361-381. doi: http://dx.doi.org/10.1002/bdm.752

Lichtenstein, S., \& Slovic, P. (2006). The construction of preference: Cambridge University Press. 
Pre-publication version

\section{SOCIAL EXCLUSION AND DECISION MAKING}

Lustenberger, D. E., \& Jagacinski, C. M. (2010). Exploring the Effects of Ostracism on Performance and Intrinsic Motivation. Human Performance, 23, 283-304-283-304. doi: http://dx.doi.org/10.1080/08959285.2010.501046

Morey, R. D., Rouder, J. N., Jamil, T., \& Morey, M. R. D. (2015). Package 'BayesFactor'. Retrieved from http://cran.r-project.org/web/packages/BayesFactor/BayesFactor.pdf

Noori, M. (2016). Cognitive reflection as a predictor of susceptibility to behavioral anomalies

$11,114-120$.

Oechssler, J., Roider, A., \& Schmitz, P. (2009). Cognitive abilities and behavioral biases. Journal of Economic Behavior \&amp; Organization, 72, 147-152-147-152. doi: http://dx.doi.org/10.1016/j.jebo.2009.04.018

Pennycook, G., Fugelsang, J. A., \& Koehler, D. J. (2015). Everyday consequences of analytic thinking. CURRENT DIRECTIONS IN PSYCHOLOGICAL SCIENCE.

Plessner, H., \& Czenna, S. (2008). The benefits of intuition. In H. Plessner, C. Betsch \& T. Betsch (Eds.), Intuition in judgment and decision making (pp. 251-265).

Preller, K. H., Pokorny, T., Hock, A., Kraehenmann, R., Stämpfli, P., Seifritz, E., et al. (2016). Effects of serotonin 2A/1A receptor stimulation on social exclusion processing. Proceedings of the National Academy of Sciences, 113, 5119-5124. doi: 10.1073/pnas. 1524187113

Sanfey, A. G., \& Chang, L. J. (2008). Multiple Systems in Decision Making. Annals of the New York Academy of Sciences, 1128, 53-62. doi: 10.1196/annals.1399.007

Shilling, A. A., \& Brown, C. M. (2016). Goal-driven resource redistribution: An adaptive response to social exclusion. Evolutionary Behavioral Sciences, 10, 149. 
Pre-publication version

\section{SOCIAL EXCLUSION AND DECISION MAKING}

Shiloh, S., Salton, E., \& Sharabi, D. (2002). Individual differences in rational and intuitive thinking styles as predictors of heuristic responses and framing effects. Personality and Individual Differences, 32, 415-429. doi: 10.1016/S0191-8869(01)00034-4

Sinayev, A., \& Peters, E. (2015). Cognitive reflection vs. calculation in decision making. Frontiers in Psychology, 6. doi: 10.3389/fpsyg.2015.00532

Sloman, S. A. (1996). The Empirical Case for Two Systems of Reasoning. Psychological Bulletin, 119, 3-22. doi: 10.1037/0033-2909.119.1.3

Sloman, S. A. (2002). Two systems of reasoning. In S. A. Sloman, T. Gilovich, D. Griffin \& D. Kahneman (Eds.), (pp. 379-396): Cambridge University Press.

Stanovich, K., \& West, A. (2000). Individual Differences in Reasoning: Implications for the Rationality Debate? Behavioral and Brain Sciences, 23, 645-726.

Stanovich, K. E. (1999). Who Is Rational? Studies Of Individual Differences In Reasoning: Mahwah, NJ: Lawrence Erlbaum Associates.

Strack, F., \& Mussweiller, T. (1997). Explaining the Enigmatic Anchoring Effect: Mechanisms of Selective Accessibility. Journal of Personality and Social Psychology, 73, 437-446. doi: 10.1037/0022-3514.73.3.437

Teovanović, P., Knežević, G., \& Stankov, L. (2015). Individual differences in cognitive biases: Evidence against one-factor theory of rationality. Intelligence, 50, 75-86. doi: https://doi.org/10.1016/j.intell.2015.02.008

Tice, D. M., \& Baumeister, R. F. (1990). Self-Esteem, Self-Handicapping, and SelfPresentation: The Strategy of Inadequate Practice. Journal of Personality, 58, 443464. doi: 10.1111/j.1467-6494.1990.tb00237.x

Toplak, M. E., West, R. F., \& Stanovich, K. E. (2011). The Cognitive Reflection Test as a predictor of performance on heuristics-and -biases tasks. Memory and Cognition, 39, 1275-1289. doi: 10.3758/s13421-011-0104-1 
Pre-publication version

\section{SOCIAL EXCLUSION AND DECISION MAKING}

Toplak, M. E., West, R. F., \& Stanovich, K. E. (2014). Assessing miserly information processing: An expansion of the Cognitive Reflection Test. Thinking \&amp; Reasoning, 20, 147-168. doi: http://dx.doi.org/10.1080/13546783.2013.844729

Tversky, A., \& Kahneman, D. (1974). Judgment under Uncertainty: Heuristics and Biases. Science, 185, 1124-1131. doi: 10.1126/science.185.4157.1124

Tversky, A., \& Kahneman, D. (1983). Extensional versus intuitive reasoning: The conjunction fallacy in probability judgment. Psychological Review, 90, 293-315.

Twenge, J. M., Catanese, K. R., \& Baumeister, R. F. (2002a). Social exclusion causes selfdefeating behavior. Journal of Personality and Social Psychology, 83, 606-615. doi: $10.1037 / 0022-3514.83 .3 .606$

Twenge, J. M., Catanese, K. R., \& Baumeister, R. F. (2002b). Social Exclusion Causes SelfDefeating Behavior. Journal of Personality and Social Psychology, 83, 606 - 615-606 -615 .

Twenge, J. M., Catanese, K. R., \& Baumeister, R. F. (2003). Social exclusion and the deconstructed state: time perception, meaninglessness, lethargy, lack of emotion, and self-awareness. Journal of personality and social psychology, 85, 409.

Van Beest, I., Williams, K. D., \& Van Dijk, E. (2011). Cyberbomb: Effects of being ostracized from a death game. Group Processes \&amp; Intergroup Relations, 14, 581-596. doi: http://dx.doi.org/10.1177/1368430210389084

Viechtbauer, W. (2010). Conducting meta-analyses in R with the metafor package. Journal of Statistical Software, 36, 1-48.

Walasek, L., Juanchich, M., \& Sirota, M. (2018). Adaptive cooperation in the face of social exclusion.

Walasek, L., Matthews, W. J., \& Rakow, T. (2015). The need to belong and the value of belongings: Does ostracism change the subjective value of personal possessions? 
Pre-publication version

\section{SOCIAL EXCLUSION AND DECISION MAKING}

Journal of Behavioral and Experimental Economics, 58, 195-204. doi:

10.1016/j.socec.2015.04.012

Warburton, W. A., Williams, K. D., \& Cairns, D. R. (2006). When ostracism leads to aggression: The moderating effects of control deprivation. Journal of Experimental Social Psychology, 42, 213-220. doi: http://dx.doi.org/10.1016/j.jesp.2005.03.005

Watson, D., Clark, L. A., \& Tellegen, A. (1988). Development and validation of brief measures of positive and negative affect: the PANAS scales. Journal of Personality and Social Psychology, 54, 1063-1070.

Welsh, M. B., Burns, N. R., \& Delfabbro, P. H. (2013). The Cognitive Reflection Test: how much more than Numerical Ability? Paper presented at the CogSci 2013 Proceedings.

Williams, K. D. (2007). Ostracism. Annual Review of Psychology, 58, 452-452. doi: http://dx.doi.org/10.1146/annurev.psych.58.110405.085641

Williams, K. D. (2009). Chapter 6 Ostracism: A Temporal Need-Threat Model Advances in Experimental Social Psychology (Vol. 41, pp. 275-314): Academic Press.

Williams, K. D., Cheung, C. K. T., \& Choi, W. (2000). Cyberostracism: Effects of being ignored over the Internet. Journal of Personality and Social Psychology, 79, 748-762. doi: http://dx.doi.org/10.1037/0022-3514.79.5.748

Williams, K. D., \& Jarvis, B. (2006). Cyberball: a program for use in research on ostracism and inter-personal acceptance. Behavior Research Methods, Instruments, \&amp; Computers, 38, . 38, 174-180-174-180.

Xu, M., Qi, S., Li, Z., Diao, L., Fan, L., Zhang, L., et al. (2017). Social exclusion weakens storage capacity and attentional filtering ability in visual working memory. Social Cognitive Affective Neuroscience. doi: 10.1093/scan/nsx139

Zadro, L., Williams, K. D., \& Richardson, R. (2004). How low can you go? Ostracism by a computer is sufficient to lower self-reported levels of belonging, control, 
Pre-publication version

\section{SOCIAL EXCLUSION AND DECISION MAKING}

selfesteem,and meaningful existence. Journal of Experimental Social Psychology, 40, 560-567.-560-567. doi: http://dx.doi.org/10.1016/j.jesp.2003.11.006

Zhou, X., He, L., Yang, Q., Lao, J., \& Baumeister, R. F. (2012). Control deprivation and styles of thinking. Journal of Personality and Social Psychology, 102, 460-478. doi: $10.1037 / \mathrm{a} 0026316$ 